\title{
Patients' preferences for osteoporosis drug treatment: a discrete choice experiment
}

\author{
E. W. de Bekker-Grob • M. L. Essink-Bot • \\ W. J. Meerding $\cdot$ H. A. P. Pols $\cdot$ B. W. Koes • \\ E. W. Steyerberg
}

Received: 5 October 2007 / Accepted: 16 November 2007 / Published online: 8 January 2008

(C) The Author(s) 2007

\begin{abstract}
Summary Active case finding for osteoporosis is used to identify patients at high fracture risk who may benefit from preventive drug treatment. We investigated the relative weight that women place on various aspects of preventive drugs in a discrete choice experiment. Our patients said they were prepared to take preventive drugs even if side effects were expected.

Introduction Active case finding for osteoporosis is used to identify patients who may benefit from preventive drugs. We aimed to elicit the relative weight that patients place on various aspects of preventive drug treatment for osteoporosis. Methods We designed a discrete choice experiment, in which women had to choose between drug profiles that differed in five treatment attributes: effectiveness, side effects (nausea), total treatment duration, route of drug administration, and out-of-pocket costs. We included 120 women aged 60 years and older, identified by osteoporosis case finding in 34 general practices in the Netherlands. A conditional logit regression model was used to analyse the
\end{abstract}

E. W. de Bekker-Grob $(\bowtie) \cdot$ M. L. Essink-Bot • W. J. Meerding •

E. W. Steyerberg

Department of Public Health,

Erasmus MC-University Medical Center Rotterdam,

P.O. Box 2040, 3000 CA Rotterdam, The Netherlands

e-mail: e.debekker@erasmusmc.nl

H. A. P. Pols

Department of Internal Medicine,

Erasmus MC-University Medical Center Rotterdam,

Rotterdam, The Netherlands

B. W. Koes

Department of General Practice,

Erasmus MC-University Medical Center Rotterdam,

Rotterdam, The Netherlands relative importance of treatment attributes, the trade-offs that women were willing to make between attributes, and their willingness to pay.

Results All treatment attributes proved to be important for women's choices. A reduction of the relative 10-year risk of hip fracture by $40 \%$ or more by the drug was considered to compensate for nausea as a side effect. Women were prepared to pay an out-of-pocket contribution for the currently available drug treatment (bisphosphonate) if the fracture risk reduction was at least $12 \%$.

Conclusions Women identified by active osteoporosis case finding stated to be prepared to take preventive drugs, even if side effects were expected and some out-of-pocket contribution was required.

Keywords Discrete choice experiment - Drug treatment . Osteoporosis $\cdot$ Preferences $\cdot$ Prevention

\section{Introduction}

Osteoporosis constitutes a major public health problem. In the USA, approximately 1.5 million fractures annually are attributable to osteoporosis, including 700,000 vertebral fractures, 250,000 distal forearm (Colles') fractures, 250,000 hip fractures, and 300,000 fractures of other limb sites [1]. Osteoporotic fractures have a major economic impact on society and on the quality of life of patients [2, 3]. Preventive drug treatments, such as bisphosphonates (alendronate, etidronate, and risedronate) reduce the risk of osteoporotic fractures in women with postmenopausal osteoporosis by stabilising or increasing the bone density [4-8]. Various practice guidelines recommend a casefinding approach to identify persons with a high risk of osteoporotic fractures $[9,10]$. Once identified, women are 
commonly prescribed preventive drug treatments. However, insight into the relative importance of attributes of preventive drug treatment (such as a bisphosphonate) is limited. Ideally, patients with high fracture risks make an informed decision on taking preventive medication, based on deliberative trade-offs between the burden of medication (e.g., duration, side effects), individual fracture risk, and treatment efficacy.

This study investigated patients' preferences for preventive drug treatment for osteoporosis by means of a discrete choice experiment (DCE), where attributes of hypothetical drug treatments were systematically varied. DCEs have increasingly been used in health care as an approach to elicit patient preferences [11-15]. The DCE was used to determine the trade-offs that community-dwelling elderly women make between the different treatment attributes, and their willingness to pay for each attribute. We also investigated whether high-risk patients (i.e., 10-year risk of a hip fracture greater than 6\%) had different preferences than low-risk patients.

\section{Materials and methods}

Study sample and elicitation mode

We recruited community-dwelling elderly women (aged over 60 years) from 34 general practices (in the area of Rotterdam, the Netherlands), who participated in a study on osteoporosis case finding. This latter study used a simple risk score to identify women at high risk of osteoporotic fractures, based on Dutch guidelines [9, 10]. After completion of the risk score, women were asked if they were willing to participate in the current study. Women were informed about their lifetime fracture risk (low or high). We aimed to administer the DCE questionnaire to 120 women with an overrepresentation of women with a high fracture risk $(n=60)$. Earlier studies have shown that this number of respondents is sufficiently large for reliable statistical analyses [15-19].

The DCE questionnaire was sent by post and a trained medical student collected the answers from the respondent by telephone a week later.

\section{DCE}

DCEs assume that a given healthcare intervention or treatment can be described by its characteristics (attributes) and that any woman's preferences for an intervention or treatment are determined by the levels of the attributes [15]. Attributes should be identified beforehand as potentially important for the choice of an intervention or treatment [20]. The relative importance of attributes and the trade-offs that women make between them can be assessed when women are offered a series of choices between treatment alternatives that have different combinations of attribute levels [21].

Attributes and attribute levels

The choice of attributes and the attribute levels was based on a literature review focusing on bisphosphonates, expert interviews ( $\mathrm{n}=5$; three GPs, the director of the Dutch Osteoporosis Foundation, and a specialist in internal medicine), and personal interviews with 15 community-dwelling women aged over 60 years (i.e., the target group) with and without osteoporosis $(\mathrm{n}=10$ and $\mathrm{n}=5$, respectively). We asked experts and women in the interviews to comment on and complete the list of treatment attributes that was created from literature review. We also asked women to rank the attributes from most important to less important with respect to their preferences for osteoporosis treatment. The number of attributes in a DCE is limited (due to impact on the random component variability) [22], and the ranking results allowed us to make an a priori selection of the most relevant attributes. These were: effectiveness of treatment, side effect of treatment (nausea), total treatment duration, route of drug administration, and costs (Table 1). Most of the attribute levels of preventive drug treatment for osteoporosis in our experiment were directly related to bisphosphonates. We also included some hypothetical levels. By including hypothetical levels we can extend the assessment of preferences beyond the currently available treatments for osteoporosis to treatments that are not yet traded in real markets, but may become available in the future. The results are potentially useful to guide the development of new drugs for osteoporosis, because we identified what is important for such a drug to be accepted by the target group. The interviews helped us to determine the hypothetical attribute levels. For example, we determined the levels for the cost-attribute by asking women directly their willingness to pay for preventive drug treatment for osteoporosis.

Study design and questionnaire

The combination of attributes and attribute levels (four attributes with four levels, and one attribute with two levels) resulted in 512 hypothetical drug treatment profiles $\left(4^{4} * 2^{1}\right)$. For obvious practical reasons, not all of these could be used in a questionnaire. Therefore, we generated a sample of hypothetical drug treatment profiles from all these 512 drug profiles for the questionnaire (i.e., we used a fractional factorial design) [23]. This sample must be large enough to estimate at least all main effects in a regression analysis. In our case, a sample of 16 hypothetical drug treatment profiles was sufficient [22]. Based on these 16 drug treatment profiles, choice sets were created. Each choice set consisted 
Table 1 Attributes and levels for osteoporosis drug treatment

\begin{tabular}{ll}
\hline Attributes and levels & $\begin{array}{l}\text { Beta coefficients in } \\
\text { regression analysis }\end{array}$ \\
\hline Route of drug administration: & \\
Tablet once a month (TABLETmonthly) & \\
Tablet once a week (TABLETweekly) & $\beta_{1}$ \\
Injection by GP every four months & $\beta_{2}$ \\
(INJECTIONfourmonths) & \\
Injection by GP every month & $\beta_{3}$ \\
(INJECTIONmonthly) & \\
$10-$ year risk redution of a hip fracture (\%) & $\beta_{4}$ \\
(EFFECTIVENESS): & \\
5 & \\
10 & \\
25 & \\
50 & \\
Nausea (for up to two hours after intake) & $\beta_{5}$ \\
(NAUSEA): & \\
No (0) & \\
Yes (1) & \\
Total treatment duration (years) (TIME) & $\beta_{6}$ \\
1 & \\
2 & \\
5 & \\
10 & \\
Total cost to you ( & \\
0 & \\
120 & \\
240 & \\
720 & \\
& \\
&
\end{tabular}

of two drug treatment profiles and a 'no drug' treatment option; see Fig. 1 for an example. The first drug treatment profile (i.e., Treatment A) of each choice set was always one of the 16 hypothetical drug treatment profiles selected for the fractional factorial design. We created the second drug treatment profile (i.e., Treatment B) of each choice set by means of a specific technique ('foldover') to ensure minimal overlap of attribute levels (i.e., Treatment A and Treatment B always had different attribute levels in each choice set). Too much overlap would reduce the information obtained on trade-offs between attribute levels. Our questionnaire contained 16 choice sets (see Appendix 1). We included a dominant choice set in the questionnaire to test for rationality (i.e., a choice set including one drug treatment profile characterized by logically preferable levels on all attributes). The questionnaire started with a detailed written description of each attribute and its levels (the complete questionnaire is available from the authors on request). The questionnaire was pilot tested $(n=10)$ to check for any problems in interpretation and face validity.

\section{Analyses}

The DCE was analysed by taking each choice among the three options (two drug treatment profiles, and a 'no drug' treatment option) as an observation. Data from respondents who failed the dominant question were excluded from further analyses. The remaining observations were analysed by a conditional logit regression model. Assuming that all attributes have an independent influence on a woman's preference, the following model was estimated [22]:

$$
\begin{aligned}
V= & \beta_{0}+\beta_{1} \text { TABLETweekly }+\beta_{2} \text { INJECTIONfourmonths } \\
& +\beta_{3} \text { INJECTIONmonthly }+\beta_{4} \text { EFFECTIVENESS } \\
& +\beta_{5} \text { NAUSEA }+\beta_{6} \text { TIME }+\beta_{7} \text { COST }
\end{aligned}
$$

where

- V represents the utility derived for preventive osteoporosis drug treatment.

- $\quad \beta_{0}$ is a constant reflecting the respondents' preference for receiving osteoporosis drug treatment relative to no osteoporosis drug treatment.
Fig. 1 Example of a choice set as presented in the questionnaire
Please, compare 'Treatment A' with 'Treatment B', and 'No treatment'. Which preventive treatment for osteoporosis do you prefer?

\begin{tabular}{|c|c|c|c|}
\hline & Treatment A & Treatment B & No treatment \\
\hline $\begin{array}{c}\text { Route of drug } \\
\text { administration }\end{array}$ & $\begin{array}{c}\text { Tablet } \\
\text { once a week }\end{array}$ & $\begin{array}{c}\text { Injection by GP } \\
\text { every 4 months }\end{array}$ & Not applicable \\
\hline $\begin{array}{c}\text { 10-year risk reduction of } \\
\text { a hip fracture }\end{array}$ & $10 \%$ & $25 \%$ & $0 \%$ \\
\hline $\begin{array}{c}\text { Nausea (during two } \\
\text { hours after use) }\end{array}$ & Yes & No & No \\
\hline Total treatment duration & 2 years & 5 years & 0 years \\
\hline $\begin{array}{c}\text { Total cost to you } \\
\text { thus per month) }\end{array}$ & $\begin{array}{c}€ 0 \\
(€ 0)\end{array}$ & $\begin{array}{c}€ 120 \\
(€ 2)\end{array}$ & $(€ 0)$ \\
\hline Which treatment & 0 Treatment A & 0 Treatment B & 0 No treatment
\end{tabular}

do you prefer? 
- $\beta_{1}$ to $\beta_{7}$ are coefficients that indicate the relative importance of each attribute (Table 1). $\beta_{1}$ to $\beta_{3}$ are dummy variables of the attribute 'route of drug administration', with tablet once a month as the base level.

The absolute value of $\mathrm{V}$ has no direct interpretation [22]. The sign of a coefficient reflects whether the attribute has a positive or negative effect on utility. The value of a coefficient indicates the relative importance of the corresponding attribute. A statistically significant coefficient was interpreted as indicating that the respondent considered the attribute important. A priori we expected all attributes to be important, and that only the attribute 'effectiveness' would have a positive effect. The utility from the 'no drug' treatment option was normalized to zero. The trade-offs that the respondents were willing to make between the attributes were estimated by the ratios of the coefficients. For example, $\beta_{5} / \beta_{6}$ represents an estimate of how much longer the respondent is willing to take osteoporosis drug treatment (in years) to avoid nausea. The value of coefficient $\beta_{7}$ is used to estimate the willingness to pay (WTP). For example, the WTP to avoid nausea was estimated as $\beta_{5} /-\beta_{7}$, where $\beta_{7}$ represents the importance of a 100 euro change in price.

We conducted a subgroup analysis by using interaction terms in the conditional logit regression model to assess whether high-risk patients (i.e., 10-year risk of a hip fracture higher than $6 \%$ ) had different preferences than low-risk patients.

\section{Results}

\section{Respondents}

Of the 181 women (76 low and 105 high fracture risk patients) invited, 120 responded (overall response rate 120/
$181=66 \% ; 60 / 76(79 \%)$ and $60 / 105(57 \%)$ for low and high fracture risk patients, respectively). Low and high fracture risk patients did not differ in educational level $\left(\chi^{2}\right.$ test, $p=$ 0.22 ), but the high fracture risk patients were older, and more frequently lived without a partner (Table 2).

\section{DCE results}

Most women indicated that they found the DCE questions (very) clear and had no difficulty in completing the questionnaire. In total, 117 of 120 women (98\%) passed the dominant question. All coefficients were significant (Table 3). All signs were consistent with a priori expectations. The positive constant term suggests that respondents preferred drug treatment over 'no drug' treatment if all other attributes were set to zero. The positive sign of the coefficient 'effectiveness' indicates that women preferred a drug treatment with a higher risk reduction of 10-year risk of a hip fracture over a drug treatment with a lower risk reduction. The negative signs for the other coefficients indicate that women preferred a cheaper and shorter drug treatment without nausea. A monthly tablet was preferred to other routes of drug administration (i.e., weekly tablet or injection).

The magnitude of the attribute coefficients corresponds with the relative importance of the attributes. For a correct interpretation of the comparison of the coefficients of the attributes, we need to pay attention to the different units of measurement. For example, the coefficient of 0.28 of 'effectiveness' implies the increase in utility per $10 \%$ of risk reduction. A risk reduction of $40 \%$ is four times larger than $10 \%$ risk reduction. Thus, a risk reduction of $40 \%$ implies a utility of 1.10 for the attribute 'effectiveness' (i.e., four multiplied with the coefficient of 0.28 of 'effectiveness'). A superficial comparison of the coefficients in Table 3 may
Table 2 Respondent characteristics

${ }^{a}$ Significant difference between low and high fracture risk patient groups

*Significant at the 5\% level

\begin{tabular}{|c|c|c|c|c|c|c|c|}
\hline \multirow[b]{2}{*}{ Group } & \multicolumn{2}{|c|}{ All patients $(\%)$} & \multicolumn{2}{|c|}{$\begin{array}{l}\text { Low fracture risk } \\
\text { patients }(\%)\end{array}$} & \multicolumn{2}{|c|}{$\begin{array}{l}\text { High fracture risk } \\
\text { patients }(\%)\end{array}$} & \multirow[t]{2}{*}{$\mathrm{P}$ value } \\
\hline & 120 & $(100)$ & 60 & $(50.0)$ & 60 & $(50.0)$ & \\
\hline Age (years) & & & & & & & $<0.001 *$ \\
\hline $60-64$ & 28 & $(23.3)$ & 21 & $(35.0)$ & 7 & (11.7) & \\
\hline $64-69$ & 18 & $(15.0)$ & 11 & (18.3) & 7 & (11.7) & \\
\hline $70-74$ & 20 & $(16.7)$ & 17 & $(28.3)$ & 3 & $(5.0)$ & \\
\hline $75-79$ & 28 & (23.3) & 10 & (16.7) & 28 & $(30.0)$ & \\
\hline 80 and older & 26 & $(21.1)$ & 1 & $(1.7)$ & 25 & (41.7) & \\
\hline Household & & & & & & & $<0.001^{*}$ \\
\hline Single & 53 & $(44.2)$ & 17 & $(28.3)$ & 36 & $(60.0)$ & \\
\hline With partner & 67 & $(55.8)$ & 43 & (71.7) & 24 & $(40.0)$ & \\
\hline Educational level & & & & & & & 0.215 \\
\hline Low & 63 & $(52.5)$ & 31 & $(51.7)$ & 32 & $(53.3)$ & \\
\hline Intermediate & 46 & $(38.3)$ & 26 & $(43.3)$ & 20 & (33.3) & \\
\hline High & 11 & $(9.2)$ & 3 & $(5.0)$ & 8 & (13.3) & \\
\hline
\end{tabular}


Table 3 Women's preferences for preventive osteoporosis drug treatment

* Significant at the 5\% level Number of observations 5,589 (117 respondents $\times 16$ choices $\times$ 3 options per choice, minus 27 missing values), pseudo $\mathrm{R}^{2}=0.1847$, log pseudolikelihood $=-1668.7$

\begin{tabular}{lllll}
\hline Attribute & Beta coefficient & P value & \multicolumn{2}{l}{$95 \%$ CI } \\
\hline Constant (drug treatment) & 1.23 & $<0.001^{*}$ & 0.81 & 1.66 \\
Drug administration (basel level tablet once a month): & & & \\
$\quad$ Table once a week & -0.31 & $<0.001^{*}$ & -0.45 & -0.17 \\
Injection every four months & -0.21 & $0.027^{*}$ & -0.41 & -0.02 \\
Injection once a month & -0.44 & $<0.001^{*}$ & -0.64 & -0.25 \\
Effectiveness (10\% risk reduction) & 0.28 & $<0.001^{*}$ & 0.23 & 0.34 \\
Side effect nausea & -1.10 & $<0.001^{*}$ & -1.30 & -0.89 \\
Treatment duration (1 year) & -0.04 & $<0.001^{*}$ & -0.06 & -0.02 \\
Cost (100) & -0.15 & $<0.001^{*}$ & -0.18 & -0.11 \\
\hline
\end{tabular}

easily lead us to the wrong conclusion that nausea as a side effect had a larger influence on women's choices for preventive drug treatment than the attribute 'effectiveness'. As shown in the computation above, a risk reduction of more than $40 \%$ contributes more to the utility of a preventive drug treatment for osteoporosis than absence of nausea. A $40 \%$ risk reduction (i.e., utility 1.10 ) compensates for the disutility of minus 1.10 of the attribute 'nausea'.

A positive utility value of a specific drug profile indicates a preference for that treatment to no treatment. The utility of a currently most frequently used preventive osteoporosis drug treatment (bisphosphonate taken as a weekly tablet, approximately 30\% fracture risk reduction, nausea as a possible side effect, total treatment duration of five years, and no out-of-pocket payment) equals

$$
\begin{aligned}
V= & 1.23-0.31(\text { TABLETweekly })+3.0 \\
& * 0.28(\text { EFFECTIVENESS })-1.10(\text { NAUSEA })-5 \\
& * 0.04(\text { TIME })-0 * 0.15(\text { COST })=0.46
\end{aligned}
$$

This outcome has a positive sign. Thus, the women in our sample preferred this drug treatment over no treatment.

\section{Trade-offs}

Based on the expressed preferences, women were prepared to adhere to drug treatment an estimated 5.7 years longer to change from an injection every 4 months to a tablet once a month, if all other attributes remained constant (Table 4). For every $10 \%$ additional fracture risk reduction, they were prepared to adhere to drug treatment 7.5 years longer. Respondents were willing to pay an extra total amount of 752 to avoid nausea as a side effect, or 26 for every 1-year decrease in total drug treatment duration.

For bisphosphonates, we estimated that respondents were willing to pay up to an estimated 338 euro out-ofpocket payment to receive treatment compared with no treatment (WTP $=847$ (constant)-212 (weekly tablet) + $3.0 * 195$ (risk reduction) -752 (side effect nausea) $-5 * 26$ (treatment duration)). They would thus be willing to pay for this treatment if the fracture risk reduction was at least $12 \%$ (see Appendix 2).

Table 4 Women's time and monetary trade-offs for preventive osteoporosis drug treatment

\begin{tabular}{llll}
\hline Attribute & $\begin{array}{l}\text { Willingness to adhere } \\
\text { to the drug treatment } \\
\text { longer (years) }\end{array}$ & $\begin{array}{l}\text { WTP for total } \\
\text { treatment }(€)\end{array}$ & Interpretation note \\
\hline $\begin{array}{l}\text { Constant (no drug treatment) } \\
\text { Drug administration (base level tablet once a month): }\end{array}$ & 32.7 & 212 & For drug treatment vs. no drug treatment \\
Tablet once a week & 8.2 & 147 & For change from tablet once a week to tablet once a month \\
Injection every 4 months & 5.7 & 304 & $\begin{array}{l}\text { For change from injection every } 4 \text { months to tablet once a month } \\
\text { Injection once a month }\end{array}$ \\
$\begin{array}{l}\text { Effectiveness } \\
\text { Side effect nausea }\end{array}$ & 7.5 & 195 & $\begin{array}{l}\text { For change from injection once a month to tablet once a month } \\
\text { Treatment duration }\end{array}$ \\
Cost & 29.0 & 752 & $\begin{array}{l}\text { For change from side effect to no side effect } \\
\text { For 1-year decrease in total drug treatment duration }\end{array}$ \\
\hline
\end{tabular}

WTP $=$ willingness to pay 
High versus low Fracture risk patients

The results of conditional logit regression modelling of data from both risk groups are presented in Table 5. Only the interaction between the effectiveness of treatment and risk group was significant $(p=0.05)$. Lower levels of effectiveness of the preventive drug treatment for osteoporosis were more acceptable to high-risk patients than to low-risk patients. High-risk patients therefore accepted a less effective drug to reduce their fracture risk.

\section{Discussion}

Women identified by active case finding for osteoporosis said in this DCE that they were prepared to adhere to preventive drug treatment. Treatment effectiveness (hip fracture risk reduction), side effects (nausea), total treatment duration, route of drug administration, and out-of-pocket costs were all relevant to women's preferences for drug treatment. Nausea as a side effect had a large influence on women's choices, though a risk reduction of $40 \%$ or more was sufficient to make nausea as a side effect acceptable. Patients with high fracture risk were more prepared to take a less effective drug treatment than low fracture risk patients.

This study illustrated the feasibility of DCE to elicit elderly women's preferences for osteoporosis drug treatment. An acceptable fraction of potential respondents agreed to participate in the experiment, and only 3 of 120 failed the dominant question. This study therefore adds to the available literature on the usefulness of DCE to investigate preferences for drug treatment [15, 24-26].

In a previous DCE investigating women's preferences for osteoporosis treatment, early postmenopausal women were willing to use a tablet once a week if the drug reduced the absolute lifetime risk of fracture by at least $10 \%$ [27]. In our study, we considered relative reductions in 10-year risk of a hip fracture, which limits the comparability between these two DCEs. According to Fraenkel et al., women willing to consider a drug treatment strongly preferred taking a tablet once a week rather than having an injection in a doctor's office. We also found that women preferred a tablet once a week to injection once a month, but that an injection in a doctor's office every 4 months was preferred to having to take a tablet once a week. This was in line with findings of another study which showed that many women preferred annual injections to weekly oral medication [28].

The women in our study showed a very positive attitude towards preventive drug treatment for osteoporosis, and said they were prepared to take preventive drug treatment even when the effectiveness of the treatment was zero. This may reflect a kind of placebo effect for drug treatment. In practice, a substantial proportion of women discontinue treatment with bisphosphonates [29, 30]. Various patient characteristics (e.g., being retired) were associated with a high compliance with treatment for osteoporosis [31]. Further research is needed to investigate why patients, who are prepared to start with bisphosphonates, discontinue treatment.

The effectiveness of the preventive osteoporosis drug treatment was less important for high-risk patients than for low-risk patients. All patients had knowledge of lifetime fracture risk (low or high). Patients at high risk were probably more aware of the consequences of their fracture risk than low-risk patients, and were therefore more prepared to take a less effective drug treatment.

In our study we used a postal questionnaire and the answers of the respondent were collected later by telephone. The use of an interviewer can be regarded as a strength in the design, because this procedure led to data completeness as well as a check of a respondent's understanding. However, this design also had some limitations. First, although we included nausea as the most relevant gastrointestinal side effect, other gastrointestinal side effects that are also common (e.g., stomach pain, heartburn)
Table 5 Differences between low and high-risk patients' preferences for preventive osteoporosis drug treatment

\footnotetext{
* Significant at the 5\% level Number of observations 5,589 (117 patients (i.e., 58 low-risk +59 high-risk patients) $\times 16$ choices $\times 3$ options per choice, minus 27 missing values), pseudo $\mathrm{R}^{2}=0.1895$, log pseudo-likelihood $=-1658.8$
}

\begin{tabular}{llll}
\hline Attribute & $\begin{array}{l}\text { Beta coefficient of low } \\
\text { risk patients }\end{array}$ & $\begin{array}{l}\text { Beta coefficient of high } \\
\text { risk patients }\end{array}$ & P value \\
\hline Constant (drug treatment) & 1.178 & 1.316 & 0.748 \\
Drug administration (basel level tablet & once a month): & & \\
Table once a week & -0.360 & -0.255 & 0.464 \\
Injection every 4 months & -0.125 & -0.317 & 0.323 \\
Injection once a month & -0.445 & -0.454 & 0.966 \\
Effectiveness (1\% risk reduction) & 0.023 & 0.034 & $0.050^{*}$ \\
Side effect nausea & -1.046 & -1.161 & 0.582 \\
Treatment duration (1 year) & -0.033 & -0.045 & 0.583 \\
Cost (1 euro) & -0.002 & -0.001 & 0.435 \\
\hline
\end{tabular}


were not included in the DCE. More in general, we selected the most relevant attributes in our DCE using interviews, but this careful procedure does not guarantee that attributes that we did not include are irrelevant to women's preferences for osteoporosis treatment. Second, we studied main effects only, since these generally account for $70 \%$ to $90 \%$ of explained variance in a DCE [22]; specific combinations of attribute levels may have specific effects that remained unidentified. Third, the current results could be validated by comparison with actual behaviour of women in drug treatment for osteoporosis. Fourth, the respondents were women selected by active case finding, which precludes generalization of the findings to all women. On the other hand, women identified by active osteoporosis case finding are those who will have to decide about treatment and therefore constitute the most relevant study group.

Patient-centered and demand-led care is becomingly increasingly important in current medical practice. Understanding which and how drug treatment attributes influence women's preferences for osteoporosis drug treatment is important to optimize the treatment design that patients will follow. The present study showed that the target group may well accept the currently available bisphosphonates with sufficient margin (satisfactory effectiveness, side effects, and so on); this is an important result for policy decision-making on the introduction of active case finding on a large scale, in addition to considerations related to cost-effectiveness.

In conclusion, this DCE showed that women identified by active osteoporosis case finding showed a positive attitude to preventive drug treatment, even if side effects (such as nausea) were expected and some out-of-pocket contribution was required.

Acknowledgements The authors thank Verity Watson $\mathrm{PhD}$ (Health Economics Research Unit, Institute of Applied Health sciences, University of Aberdeen, Scotland) for her helpful advice in analyzing the DCE and for her comments on this paper.

Funding The Netherlands Organization for Health Research and Development (ZonMw) funded this research (grant number: 945-14-010 HTA).

Open Access This article is distributed under the terms of the Creative Commons Attribution Noncommercial License which permits any noncommercial use, distribution, and reproduction in any medium, provided the original author(s) and source are credited.

\section{Appendix}

Appendix 1

Overview of the 16 choice sets used in our questionnaire.

\begin{tabular}{|c|c|c|c|c|c|c|c|c|c|}
\hline \multirow[b]{3}{*}{ Choice set } & \multirow{2}{*}{\multicolumn{4}{|c|}{$\frac{\text { Treatment A }}{\text { Attributes }}$}} & \multirow{2}{*}{\multicolumn{5}{|c|}{$\begin{array}{c}\text { Treatment B } \\
\text { Attributes }\end{array}$}} \\
\hline & & & & & & & & & \\
\hline & I & II & III IV & $\mathrm{V}$ & I & II & III & IV & $\mathrm{V}$ \\
\hline 1 & b & $\mathrm{a}$ & $\mathrm{a} d$ & $\mathrm{~b}$ & $\mathrm{c}$ & b & b & a & \\
\hline 2 & d & $\mathrm{a}$ & b c & d & $\mathrm{a}$ & b & $\mathrm{a}$ & d & $\mathrm{a}$ \\
\hline 3 & $\mathrm{a}$ & $c$ & $b \quad d$ & $\mathrm{c}$ & $\mathrm{b}$ & d & $\mathrm{a}$ & $\mathrm{a}$ & d \\
\hline 4 & c & $\mathrm{c}$ & $\mathrm{a} \quad \mathrm{c}$ & $\mathrm{a}$ & d & $\mathrm{d}$ & b & d & $\mathrm{b}$ \\
\hline 5 & $\mathrm{a}$ & b & b c & b & b & $\mathrm{c}$ & $\mathrm{a}$ & d & $\mathrm{c}$ \\
\hline 6 & $\mathrm{a}$ & d & $\mathrm{a} \quad \mathrm{b}$ & & b & $\mathrm{a}$ & $\mathrm{b}$ & c & \\
\hline 7 & c & $\mathrm{a}$ & $b \quad b$ & c & d & $b$ & $\mathrm{a}$ & c & \\
\hline 8 & d & $\mathrm{c}$ & $\mathrm{a} \quad \mathrm{b}$ & $\mathrm{b}$ & $\mathrm{a}$ & d & $\mathrm{b}$ & $\mathrm{c}$ & \\
\hline 9 & b & $\mathrm{d}$ & $\mathrm{a} \quad \mathrm{c}$ & & $\mathrm{c}$ & $\mathrm{a}$ & $\mathrm{b}$ & d & \\
\hline 10 & d & b & a a & c & $\mathrm{a}$ & $\mathrm{c}$ & $\mathrm{b}$ & b & \\
\hline 11 & $\mathrm{a}$ & $\mathrm{a}$ & $\mathrm{a} a$ & $\mathrm{a}$ & b & $\mathrm{b}$ & b & $b$ & \\
\hline 12 & b & $\mathrm{c}$ & b a & $\mathrm{d}$ & $\mathrm{c}$ & d & $\mathrm{a}$ & b & \\
\hline 13 & b & $\mathrm{b}$ & $b \quad b$ & $\mathrm{a}$ & $\mathrm{c}$ & $\mathrm{c}$ & $\mathrm{a}$ & c & \\
\hline 14 & d & d & b d & & $\mathrm{a}$ & $\mathrm{a}$ & $\mathrm{a}$ & $\mathrm{a}$ & $\mathrm{b}$ \\
\hline 15 & c & $\mathrm{d}$ & b a & & d & $\mathrm{a}$ & $\mathrm{a}$ & b & $\mathrm{c}$ \\
\hline 16 & c & $b$ & $\mathrm{a} d$ & $\mathrm{~d}$ & $\mathrm{~d}$ & $\mathrm{c}$ & $b$ & a & \\
\hline
\end{tabular}

\section{Code book:}

I Route of drug administration

a tablet once a month

b tablet once a week

c injection by GP every 4 months

d injection by GP every month

II Effectiveness

a $5 \%$ risk reduction of a hip fracture

b $10 \%$ risk reduction of a hip fracture

c $25 \%$ risk reduction of a hip fracture

d $50 \%$ risk reduction of a hip fracture

III Side effects (nausea)

a no nausea

b nausea for up to two hours after intake

IV Total treatment duration

a 1 year

b 2 years

c 5 years

d 10 years

V Out-of-pocket costs
a $€ 0$
b $€ 120$
c $€ 240$
d $€ 720$ 
Treatment A of choice set 1 (i.e., code 'baadb') represents a hypothetical preventive drug treatment for osteoporosis with the following characteristics: tablet once a week as a route of drug administration, $5 \%$ risk reduction of a hip fracture as treatment effectiveness, no side effects (nausea), total treatment duration of 10 years, and 120 euro out-of-pocket costs for the entire treatment. In the questionnaire this treatment was presented with Treatment B of choice set 1 (i.e., code 'cbbac') with the following characteristics: injection by GP every 4 months as a route of drug administration, $10 \%$ risk reduction of a hip fracture as treatment effectiveness, nausea for up to two hours after intake as a side effect, total treatment duration of 1 year, and 240 euro out-of-pocket costs for the entire treatment. Respondents had to choose between this Treatment A, Treatment B, or no treatment.

\section{Appendix 2}

Regression line showing the relationship between risk reduction (\%) by means of bisphosphonate (tablet once a week, side effect nausea, and treatment duration five years) and WTP $(€)$

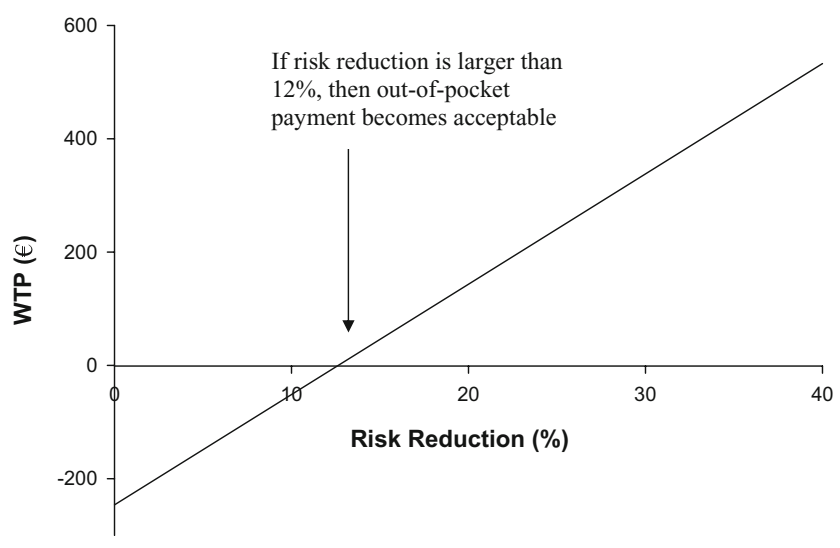

Conflicts of interest None.

\section{References}

1. Riggs BL, Melton LJ 3rd (1995) The worldwide problem of osteoporosis: insights afforded by epidemiology. Bone 17 (5 Suppl):505S-511S

2. Silverman SL (2005) Quality-of-life issues in osteoporosis. Curr Rheumatol Rep 7(1):39-45

3. Atik OS, Gunal I, Korkusuz F (2006) Burden of osteoporosis. Clin Orthop Relat Res 443:19-24

4. Ensrud KE, Black DM, Palermo L, Bauer DC, Barrett-Connor E, Quandt SA, Thompson DE, Karpf DB (1997) Treatment with alendronate prevents fractures in women at highest risk: results from the Fracture Intervention Trial. Arch Intern Med 157(22):2617-2624

5. Pols HA, Felsenberg D, Hanley DA, Stepan J, Munoz-Torres M, Wilkin TJ, Qin-sheng G, Galich AM, Vandormael K, Yates AJ et al (1999) Multinational, placebo-controlled, randomized trial of the effects of alendronate on bone density and fracture risk in postmenopausal women with low bone mass: results of the FOSIT study. Fosamax International Trial Study Group. Osteoporos Int 9 (5):461-468

6. Black DM, Cummings SR, Karpf DB, Cauley JA, Thompson DE, Nevitt MC, Bauer DC, Genant HK, Haskell WL, Marcus $\mathrm{R}$ et al (1996) Randomised trial of effect of alendronate on risk of fracture in women with existing vertebral fractures. Fracture Intervention Trial Research Group. Lancet 348(9041):15351541

7. Meunier PJ (1999) Evidence-based medicine and osteoporosis: a comparison of fracture risk reduction data from osteoporosis randomised clinical trials. Int J Clin Pract 53(2):122-129

8. Harris ST, Watts NB, Genant HK, McKeever CD, Hangartner T, Keller M, Chesnut CH 3rd, Brown J, Eriksen EF, Hoseyni MS et al (1999) Effects of risedronate treatment on vertebral and nonvertebral fractures in women with postmenopausal osteoporosis: a randomized controlled trial. Vertebral Efficacy with Risedronate Therapy (VERT) Study Group. JAMA 282(14):1344-1352

9. Guideline on osteoporosis. Utrecht: The Dutch Institute for Healthcare Improvement (CBO); 2002

10. Kanis JA, Delmas P, Burckhardt P, Cooper C, Torgerson D (1997) Guidelines for diagnosis and management of osteoporosis. The European Foundation for Osteoporosis and Bone Disease. Osteoporos Int 7(4):390-406

11. Gyrd-Hansen D, Sogaard J (2001) Analysing public preferences for cancer screening programmes. Health Econ 10(7):617-634

12. Ryan M, Hughes J (1997) Using conjoint analysis to assess women's preferences for miscarriage management. Health Econ 6 (3):261-273

13. Ryan M, Farrar S (2000) Using conjoint analysis to elicit preferences for health care. BMJ 320(7248):1530-1533

14. Sculpher M, Bryan S, Fry P, de Winter P, Payne H, Emberton M (2004) Patients' preferences for the management of non-metastatic prostate cancer: discrete choice experiment. BMJ 328(7436):382

15. Watson V, Ryan M, Brown CT, Barnett G, Ellis BW, Emberton M (2004) Eliciting preferences for drug treatment of lower urinary tract symptoms associated with benign prostatic hyperplasia. J Urol 172(6 Pt 1):2321-2325

16. Aristides M, Weston AR, FitzGerald P, Le Reun C, Maniadakis N (2004) Patient preference and willingness-to-pay for Humalog Mix25 relative to Humulin 30/70: a multicountry application of a discrete choice experiment. Value Health 7(4):442-454

17. Weston A, Fitzgerald P (2004) Discrete choice experiment to derive willingness to pay for methyl aminolevulinate photodynamic therapy versus simple excision surgery in basal cell carcinoma. Pharmacoeconomics 22(18):1195-1208

18. Lee A, Gin T, Lau AS, Ng FF (2005) A comparison of patients' and health care professionals' preferences for symptoms during immediate postoperative recovery and the management of postoperative nausea and vomiting. Anesth Analg 100(1):87-93

19. Bishai D, Brice R, Girod I, Saleh A, Ehreth J (2007) Conjoint analysis of French and German parents' willingness to pay for meningococcal vaccine. Pharmacoeconomics 25(2):143-154

20. Farrar S, Ryan M, Ross D, Ludbrook A (2000) Using discrete choice modelling in priority setting: an application to clinical service developments. Soc Sci Med 50(1):63-75

21. Ryan M, Scott DA, Reeves C, Bate A, van Teijlingen ER, Russell EM, Napper M, Robb CM (2001) Eliciting public preferences for 
healthcare: a systematic review of techniques. Health Technol Assess 5(5):1-186

22. Louviere JJ, Hensher DA, Swait JD (2000) Stated choice methods: analysis and application. Cambridge University Press, Cambridge

23. Hahn GJ, Shapiro SS (1966) A catalog and computer program for the design and analysis of orthogonal symmetric and asymmetric fractional factorial experiments. General Electric Research and Development Center, Schenectady, NY, USA

24. Lloyd A, McIntosh E, Price M (2005) The importance of drug adverse effects compared with seizure control for people with epilepsy: a discrete choice experiment. Pharmacoeconomics 23 (11):1167-1181

25. Mahadevia P, Shah S, Mannix S, Brewster-Jordan J, Kleinman L, Liebman C, O'Dowd L (2006) Willingness to pay for sensory attributes of intranasal corticosteroids among patients with allergic rhinitis. J Manag Care Pharm 12(2):143-151

26. Lancsar EJ, Hall JP, King M, Kenny P, Louviere JJ, Fiebig DG, Hossain I, Thien FC, Reddel HK, Jenkins CR (2007) Using discrete choice experiments to investigate subject preferences for preventive asthma medication. Respirology 12(1):127-136

27. Fraenkel L, Constantinescu F, Oberto-Medina M, Wittink DR (2005) Women's preferences for prevention of bone loss. J Rheumatol 32(6):1086-1092

28. Fraenkel L, Gulanski B, Wittink D (2006) Patient treatment preferences for osteoporosis. Arthritis Rheum 55(5):729-735

29. Bartl R, Gotte S, Hadji P, Hammerschmidt T (2006) [Adherence with daily and weekly administration of oral bisphosphonates for osteoporosis treatment] Adharenz mit taglichen und wochentlichen oralen Bisphosphonaten in der Osteoporosetherapie. Dtsch Med Wochenschr 131(22):1257-1262

30. Caro JJ, Ishak KJ, Huybrechts KF, Raggio G, Naujoks C (2004) The impact of compliance with osteoporosis therapy on fracture rates in actual practice. Osteoporos Int 15(12):1003-1008

31. Blotman F, Cortet B, Hilliquin P, Avouac B, Allaert FA, Pouchain D, Gaudin AF, Cotte FE, El Hasnaoui A (2007) Characterisation of patients with postmenopausal osteoporosis in French primary healthcare. Drugs Aging 24(7):603-614 